\title{
PENDIDIKAN KARAKTER UNTUK PERKEMBANGAN MORAL ANAK USIA DINI
}

\author{
Aisyah \\ PG-PAUD FPP Universitas PGRI Adi Buana Surabaya \\ aisyah@unipasby.ac.id
}

\begin{abstract}
Education is a very important thing for every generation of the nation that starts early. Early childhood education is a series of systematic and programmatic efforts in conducting coaching aimed at children from birth up to the age of 6 through the provision of educational stimuli to help the child's physical and spiritual growth and development have readiness to enter further education. In early childhood education has a great purpose. The big goal is to develop the potential of children early on in preparation for life that can adapt to the environment. Early childhood character education is very important. This is in order for the child to have good moral behavior. They learn to understand the good and the bad from what they do. Environmental influences greatly influence the moral development of children such as playmates, educators and parents as well as the surrounding environment. In this case it is important for educators and parents to support the moral development of the child through the planting of good values, set an example with a good example, because the nature of the child is a good impersonator. So the child can imitate it.
\end{abstract}

Keywords: Character Education, Moral Development, Early Childhood.

\section{Pendahuluan}

Pendidikan merukapan suatu hal yang sangat penting bagi setiap generasi bangsa yang dimulai sejak dini Rakihmawati dan Yusmiatinengsih (2012:20. Tujuan pendidikan adalah untuk mengembangkan potensi anak sejak dini sebagai persiapan untuk hidup yang dapat menyesuaikan diri dengan lingkungan, Suyadi (2010:12).

Pendidikan anak usia dini merupakan serangkaian upaya sistematis dan terprogram dalam melakukan pembinaan yang ditujukan kepada anak sejak lahir sampai dengan usia 6 tahun yang dilakukan melalui pemberian rangsangan pendidikan untuk membantu pertumbuhan dan perkembangan jasmani serta rohani anak memiliki kesiapan untuk memasuki pendidikan lebih lanjut, Suyadi (2010:12).

Menurut Jamal Ma'mur Asmani dalam Zulnuraini (2012), Pendidikan karakter adalah segala sesuatu yang dilakukan pendidik untuk mempengaruhi peserta didik. Pendidik membatu untuk membentuk watak peserta didik dengan cara memberikan keteladanan, cara bicara atau menyampaikan materi dengan baik, 


\begin{tabular}{|c|c|c|}
\hline \multicolumn{3}{|c|}{ Jurnal Warna : Jurnal Pendidikan Dan Pembelajaran Anak Usia dini. } \\
September 2020. Vol 05. No. 02 \\
\hline Received: Agustus 2020 & Accepted: Agustus 2020 & Published: September 2020 \\
\hline & Article DOI: $10.24903 /$ jw.v5i2.528 \\
\hline
\end{tabular}

toleransi dan dan berbagai hal yang terkaitnya.

Pendidikan karakter diharapkan mampu membentuk moral anak. Susanto (2012:65) kata moral berasal dari kata Latin mos yang artinya adalah istilah adat, kebiasaan, peraturan/nilai-nilai atau tata cara kehidupan. Istilah moral dalam tulisan ini diartikan sebagai aturan, nilanilai dan kesadaran seseorang untuk menerima dan melakukan peraturan, nilai-nilai dan prinsip yang baku dan dianggap benar. Menurut Harlock dalam Rakihmawati dan Yusmiatinengsih (2012:20) moral berarti perilaku yang sesuai deng kode moral kelompok sosial, perilaku moral dikendalikan konsepkonsep moral peraturan perilaku yang menjadi kebiasaan bagi anggota suatu budaya.

Menurut Santrock dalam Rakihmawati dan Yusmiatinengsih (2012:20) menyatakan bahwa perkembangan moral adalah perubahan, penalaran, perasaan, dan perilaku tentang stantar mengenai benar dan salah. Sedangkan menurut Musfirih dalam Rakihmawati dan Yusmiatinengsih (2012:20) menyatakan bahwa perkembangan moral anak berlangsung secara berangsur-angsur tahap demi tahap. Terdapat tiga tahap dalam perkembangan ini: tahap amoral (anak tidak memiliki rasa benar dan salah), tahap konvesial (anak menerima nilainilai moral dari orang tua atau masyarakat), dan tahap otonomi ( anak membuat pilihan sendiri secara bebas).

Dalam perkembangan moral, anak usia dini masih banyak belajar tentang berbagai hal dalam kehidupannya. Anak belajar mengamati, mengenal dan berbuat sesuka mereka. Anak belajar berbagai peristiwa-peristiwa dalam kehidupannya dan dari peristiwa-peristiwa tersebut anak akan menerima pengaruh positif dan negatif serta sifat empati dalam diri anak terhadap orang lain juga berkembang juga anak dapat bimbingan dan pengarahan dari orang dewasa.

Dari penjelasan diatas dapat disimpulkan bahwa pendidikan wajib diberikan sedini mungkin dengan tujuan untuk mengembangkan potensi anak sejak dini sebagai persiapan untuk hidup yang dapat menyesuaikan diri dengan lingkungan. Selain itu anak usia dini merupakan masa golden age dimana perkembangan adak dapat dikembangkan dengan baik. Salah satunya adalah perkembangan moral anak. Perkembangan moral adalah tindakan atau perbuatan seseorang tentang yang salah untuk bertindak sesuai dengan kebiasaan suatu anggota budaya.

Dalam perkembangan moral, perana orangtua, pendidik maupun lungkungan sangat mempengaruhi anak. Maka 


\begin{tabular}{|c|c|c|}
\hline \multicolumn{4}{|c|}{ Jurnal Warna : Jurnal Pendidikan Dan Pembelajaran Anak Usia dini. } \\
September 2020.Vol 05. No. 02 \\
\hline Received: Agustus 2020 & Accepted: Agustus 2020 & Published: September 2020 \\
\hline & Article DOI: $10.24903 / j w . v 5 i 2.528$ \\
\hline
\end{tabular}

orangtua, pendidik dan lingkungan diseliling anak perlu memberikan bimbingan dan pengarahan kepada anak agar mengetahui benar dan salah dalam bertindak. Teladan yang baik akan dengan mudah diterima anak. Karena pada dasarnya anak memiliki sifat sebagai peniru apa yang dilihatnya.

Anak usia dini berada pada tahap pertumbuhan dan perkembangan gaik fisik ataupun mental secara pesat. Meriyati (2016:49) Pertumbuhan dan perkembangan ini dimulai sejak masa prenatal, yaitu sejak dalam kandungan. Masa usia dini merupakan preode awal yang paling penting dan mendasar sepanjang rentang pertumbuhan dan perkembangan kehidupan manusia karena semua potensi anak berkembang dengan cepat. Dapat disebut juga masa golden age dimana perkembangan adak dapat dikembangkan dengan baik. Salah satunya adalah perkembangan moral anak.

Karakteristik anak yang unik, aktif, rasa ingin tahunya tinggi, egosentris, berjiwa petualang, daya konsentrasi pendek, daya imajinasi tinggi, dan senang berteman sehingga anak dapat tumbuh dan berkembang dengan baik kalau mendapatkan kasih sayang, pengasuhan yang penuh pengertian dan dalam situasi yang damai dan harmonis dari orang sekitarnya.
Dengan demikian penting sekali sebagai pendidik khususnya orangtua memberikan pendidikan karakter yang baik. Salah satunya yaitu memberikan telatan yang baik kepada anak. Sebagai pendidik maupun orangtua harus memberikan contoh-contoh yang mendukung perkembangan moral anak.

Rakihmawati dan Yusmiatinengsih (2012:19) masalah yang mempengaruhi perkembangan moral anak yaitu (1) masih kurangnya pemahaman anak tentang baik dan buruk; (2) kurangnya ketertarikan anak dalam mendengarkan cerita; (3) kurangnya perhatian pendidik dan orangtua; (4) kurangnya pendidikan karakter melalui pemberian teladan yang baik.

Penulis membatasi masalah tentang pendidikan karakter untuk perkembangan moral anak usia dinisehingga menimbulkan pertanyaan “Apakah penting pendidikan karakter untuk pengembangan moral anak usia dini?".

Penelitihan ini bertujuan untuk perbaikan terhadap pendidik dan orangtua dalam pendidikan karakter melalui pemberian teladan yang baik. Tentunya penelitian ini memiliki manfaat baik bagi anak untuk menjalani kehidupan kedepannya. Untuk pendidik dan orang tua dapat mengetahui bahwa penanaman moral sejak dini sangat 


\begin{tabular}{|c|c|c|}
\hline \multicolumn{3}{|c|}{ Jurnal Warna : Jurnal Pendidikan Dan Pembelajaran Anak Usia dini. } \\
September 2020.Vol 05. No. 02 \\
\hline Received: Agustus 2020 & Accepted: Agustus 2020 & Published: September 2020 \\
\hline & Article DOI: $10.24903 / j w . v 5 i 2.528$ \\
\hline
\end{tabular}

penting untuk pertumbuhan dan perkembangan anak.

\section{Pembahasan}

Pendidikan anak usia dini merupakan serangkaian upaya sistematis dan terprogram dalam melakukan pembinaan yang ditujukan kepada anak sejak lahir sampai dengan usia 6 tahun yang dilakukan melalui pemberian rangsangan pendidikan untuk membantu pertumbuhan dan perkembangan jasmani serta rohani anak memiliki kesiapan untuk memasuki pendidikan lebih lanjut, Suyadi (2010:12). Rakihmawati dan Yusmiatinengsih (2012:21) menyatakan Usia kanak-kanak adalah usia yang sangat penting untuk dilakukan penanaman moral. Pada usia prasekolah (di bawah enam tahun) aspek emosi dan kognitif anak masih dalam perkembangan. Suyadi (2010:13) menyatakan ada 6 aspek yang harus dikembangkan dalam pendidikan anak usia dini, yaitu: (1) Nilai moral dan agama; (2) fisik motorik; (3) Kognitif; (4) Sosial emosional; (5) Bahasa, dan; (6) Seni. Ke enam aspek tersebut sangat penting untuk pertumbuhan dan perkembangan anak. Oleh karena pendidikan karakter harus diberikan sejak dini. Hal ini harus menjadi perhatian bagi pendidik dan orangtua dalam mendidik anak supaya menjadi orang berbudi luhur.
Nilai-nilai moral seseorang anak ditentukan oleh niali perilaku baik dan buruk. Terbentuknya nilai moral seseorang diperoleh melalui proses panjang. Pembentukan perilaku moral tersebut secara sengaja harus dikenalkan dan ditanamkan sejak usia dini.

Selain itu anak memiliki beberapa karakteristik yang unik, aktif, rasa ingin tahunya tinggi, egosentris, berjiwa petualang, daya konsentrasi pendek, daya imajinasi tinggi, dan senang berteman sehingga anak dapat tumbuh dan berkembang dengan baik kalau mendapatkan kasih sayang, pengasuhan yang penuh pengertian dan dalam situasi yang damai dan harmonis dari orang sekitarnya.

Dalam perkembangan moral, anak usia dini masih banyak belajar tentang berbagai hal dalam kehidupannya. Anak belajar mengamati, mengenal dan berbuat sesuka mereka. Anak belajar berbagai peristiwa-peristiwa dalam kehidupannya dan dari peristiwa-peristiwa tersebut anak akan menerima pengaruh positif dan negatif serta sifat empati dalam diri anak terhadap orang lain juga berkembang juga anak dapat bimbingan dan pengarahan dari orang dewasa.

Hermansyah dalam Rakihmawati dan Yusmiatinengsih (2012:21) memaparkan bahwa upaya menanamkan sikap dan perilaku moral kepada anak 


\begin{tabular}{|c|c|c|}
\hline \multicolumn{4}{|c|}{ Jurnal Warna : Jurnal Pendidikan Dan Pembelajaran Anak Usia dini. } \\
September 2020.Vol 05. No. 02 \\
\hline Received: Agustus 2020 & Accepted: Agustus 2020 & Published: September 2020 \\
\hline & Article DOI: $10.24903 / j w . v 5 i 2.528$ \\
\hline
\end{tabular}

usia dini dapat dilakukan melalui (1) kegiatan rutin; (2) kegiatan spontan; (3) kegiatan dengan teladan; dan (4)kegiatan yang direncanakan.

Selainitu, Inawati (2017:58) menyatakan bahwa, pengembangan moral juga dapat di berikan melalui beberapa stategis, yaitu: (1) menanamkan rasa cinta kepada Tuhan dengan membimbing adak menuju akidah yang benar; (2) menciptakan rasa aman; (3) mencium dan membelai anak maksudnya dengan memberi kasih sayang yang utuh; (4) menanamkan rasa cinta tanah air; (5) melatih dan mengamati; (6) menyentuh dan mengaktifkan potensi berfikir anak; (7) memberi penghaegaan; (8) teladan yang baik, dan; (9) memenuhi kebutuhan anak.

Susanto (2012:71) menyatakan bahwa, pentingnya keluarga dalam pembentukan karakter ini, akan berpengaruh pada sikap dan sifat-sifat yang melekat pada anak karena secara fitra Allah tidak menciptakan hambahamba-Nya dalam sifat-sifat buruk, tetapi dalam ketaatan luhur, suci, dan bersih.namunn karena pendidikan dan perhatian, serta peringatan sejak dini dari orang tua (keluarga) maupun pendidik, maka sifat-sifat buruk timbul pada diri anak. Dengan demikan perana pendidik dan orangtua dalam mendukung perkembangan moral anak melalui pendidikan karakter yang di berikan sedini mungkin sangat penting. Karena semakin dewasa, anak semakin sulit baginya untuk meninggalkan sifat-sifat buruk. Banyak sekali orang-orang dewasa yang menyadari sifat buruknya, tetapi sangat sulit mengubahnya, karena sifat buruk yang sudah kuat mengakar pada dirinya, dan menjadi kebiasaan buruk yang sulit ditinggalkan.

$$
\text { Mulyani dan Nana }
$$
menyatakan bahwa pada masa awal kanak-kanaknya, biasanya anak-anak akan mengidentifikasi dirinya dengan ayah dan ibu atau orang lain yang dekan dengannya. Dengan demikian lingkungan anak sangan mempengaruhi. Perilaku pendidik dan orangtua adalah salah satu contoh yang akan dengan mudah ditiru oleh anak. Thomson dalam Rakihmawati dan Yusmiatinengsih (2012:22) menyatakan "hubungan orangtua dan anak memperkenalkan anak kepada kewajiban mutual dan hubungan interpersonal yang erat". Kewajiban orangtua adalah terlibat dalam pengasuhan yang positif dan memandu anak menjadi manusia yang kompeten dan kewajiban anak merespon dengan sesuai terhadap inisiatif dari orangtua. Oleh karena itu penting bagi orangtua menanamkan nilai-nilai moral yang baik.

Sikap yang harus dimiliki orangtua dan pendidik dalam penerapan moral 


\begin{tabular}{|c|c|c|}
\hline \multicolumn{3}{|c|}{ Jurnal Warna : Jurnal Pendidikan Dan Pembelajaran Anak Usia dini. } \\
September 2020.Vol 05. No. 02 \\
\hline Received: Agustus 2020 & Accepted: Agustus 2020 & Published: September 2020 \\
\hline & Article DOI: $10.24903 / j w . v 5 i 2.528$ \\
\hline
\end{tabular}

anak menurut Santrock dalam

Rakihmawati dan Yusmiatinengsih

(2012:22) yaitu: (1) hangat dan mendukung, bukan menghukum; (2)

menggunakan disiplin indutif; (3)

memberikan kesempatan anak dalam

mempelajari dan memahami perasaan

orang lain; (4) melibatkan anak dalam

mengambil keputusan keluarga dan proses pemikiran mengenai keputusan moral; (5) menjadi model terhadap penalaran dan perilaku moral dan menyediakan kesempatan bagi anak untuk juga melakukan hal tersebut; (6) menyediakan informasi tentang perilaku apa yang diharapkan dan mengapa, dan; (7) membangun moralitas internal dan eksternal.

Selain itu dalam pendidikan karakter anak juga dapat dipengaruhi melalui lingkungan main, seperti teman main. Menurut Kohlberg dalam Rakihmawati dan Yusmiatinengsih (2012:22) menyatakan, "interaksi dengan teman sebaya adalah agian penting dalam stimulisi yang menantang anak untuk mengubah penalaran moral mereka". Proses menerima dan memberi diantara teman sebaya memberikan kesempatan pada anak untuk mengabil perspektif orang lain dan menghasilkan peraturan secara demokratis hubungan teman sebaya memberikan kesempatan pada 


\begin{tabular}{|c|c|c|}
\hline \multicolumn{3}{|c|}{ Jurnal Warna : Jurnal Pendidikan Dan Pembelajaran Anak Usia dini. } \\
September 2020.Vol 05. No. 02 \\
\hline Received: Agustus 2020 & Accepted: Agustus 2020 & Published: September 2020 \\
\hline & Article DOI: $10.24903 / j w . v 5 i 2.528$ \\
\hline
\end{tabular}

serta rohani anak memiliki kesiapan untuk memasuki pendidikan lebih lanjut. Dengan tujuan untuk mengembangkan potensi anak sejak dini sebagai persiapan untuk hidup yang dapat menyesuaikan diri dengan lingkungan.

Pada masa ini pendidikan karakter anak usia dini sangatlah penting agar anak memiliki perilaku moral yang baik. Selain itu, penerapan pendidikan karakter sedini mungkin sangat baik karena pada masa itulah anak dapat mengembangkan semua aspek perkembangan, salah satunya perkembangan moral.

Perkembangan moral anak usia dini dapat ditanamkan dengan upaya menanamkan sikap dan perilaku moral kepada anak usia dini dapat dilakukan melalui (1) kegiatan rutin; (2) kegiatan spontan; (3) kegiatan dengan teladan; dan (4)kegiatan yang direncanakan. Ke empat kegiatan tersebut dapat dilakukan oleh orangtua (keluarga) dan pendidik dengan memberikan contoh atau teladan yang baik.

Selain itu pengembangan moral juga dapat di berikan melalui beberapa stategis, yaitu: (1) menanamkan rasa cinta kepada Tuhan dengan membimbing adak menuju akidah yang benar; (2) menciptakan rasa aman; (3) mencium dan membelai anak maksudnya dengan memberi kasih sayang yang utuh; (4) menanamkan rasa cinta tanah air; (5) melatih dan mengamati; (6) menyentuh dan mengaktifkan potensi berfikir anak; (7) memberi penghaegaan; (8) teladan yang baik, dan; (9) memenuhi kebutuhan anak.

Dengan contoh dan teladan yang baik anak pasti akan meniru apa yang dilihatnya, karena anak memiliki sifat sebagai peniru ulung. Selain itu sangat penting juga memberikan bimbingan dan pengarahan kepada anak agar perkembambangan moral dapat berkembang dengan efektif. Karena perana orangtua, pendidik maupun lungkungan sangat mempengaruhi anak. Dengan adanya contoh (teladan), bimbingan dan pengarahan anak akan belajar memahami baik dan buruknya dari apa yang dilakukannya.

Masalah yang mempengaruhi perkembangan moral anak yaitu (1) masih kurangnya pemahaman anak tentang baik dan buruk; (2) kurangnya ketertarikan anak dalam mendengarkan cerita; (3) kurangnya perhatian pendidik dan orangtua; (4) kurangnya pendidikan karakter melalui pemberian teladan yang baik.

\section{Saran}

Sesuai dengan permasalahan yang dibahas, hasil penelitian disarankan agar pelaksanaan pendidikan karakter diberikan sedini mungkin untuk 


\begin{tabular}{|c|c|c|}
\hline \multicolumn{3}{|c|}{ Jurnal Warna : Jurnal Pendidikan Dan Pembelajaran Anak Usia dini. } \\
September 2020. Vol 05. No. 02 \\
\hline Received: Agustus 2020 & Accepted: Agustus 2020 & Published: September 2020 \\
\hline & Article DOI: $10.24903 /$ jw.v5i2.528 \\
\hline
\end{tabular}

mendukung peerkembangan moral anak secara optimal. menanamkan sikap dan perilaku moral kepada anak usia dini dapat dilakukan melalui (1) kegiatan rutin; (2) kegiatan spontan; (3) kegiatan dengan teladan; dan (4)kegiatan yang direncanakan. Ke empat kegiatan tersebut dapat dilakukan oleh orangtua (keluarga) dan pendidik dengan memberikan contoh atau teladan yang baik.

Dengan contoh dan teladan yang baik anak pasti akan meniru apa yang dilihatnya, karena anak memiliki sifat sebagai peniru ulung. Selain itu sangat penting juga memberikan bimbingan dan pengarahan kepada anak agar perkembambangan moral dapat berkembang dengan efektif. Karena perana orangtua, pendidik maupun lungkungan sangat mempengaruhi anak. Dengan adanya contoh (teladan), bimbingan dan pengarahan anak akan belajar memahami baik dan buruknya dari apa yang dilakukannya.

Selain itu dalam memberikan pendidikan karakter, pendidik dan orangtua harus memperhatikan kegiatan anak, kegiatan anak yang berintraksi dengan lingkungan sekelilingnya. Karena pengaruh lingkungan memiliki perana penting dalam perkembangan moral anak usia dini.

\section{Daftar Pustaka}

Inawati, Asti. 2017. Strategi Pengembangan Moral dan Nilai Agama Untuk Anak Usia Dini. Dalam Jurnal Pendidikan Anak Usia Dini. Vol. 3, No. 1. 2017.

Meriyati. 2016. Membangun Karakter Anak Sejak Usia Dini. Dalam Jurnal Studi Gender dan Anak. Vol. 1, No. 1, Agustus 2016.

Rakihmawati dan Yusmiatinegsih. 2012. Upaya Meningkatkan Perkembangan Moral Anak Usia Dini Melalui Mendongeng di TK Dharmawanita. Dalam Jurnal Ilmiah VISI P2TK PAUD NI. Vol. 7, No. 1. Juni 2012.

Sumantri dan Syaodih. 2011. Perkembangan Peserta Didik. Jakarta: Universitas Terbuka.

Susanto, Ahmad. 2012. Perkembangan Anak Usia Dini Pengantar dalam Berbagai Aspek. Jakarta: Kencana Prenada Media Group.

Suyadi. 2010. Pengantar Psikologi Belajar Pendidikan Anak Usia Dini. Yogyakarta: PT Bintang Pustaka Abadi IKAPI.

Zulnuraini. 2012. Pendidikan Karakter: Konsep Implementasi dan Pengembangan di Sekolah Dasar di Kota Palu. Dalam Jurnal DIKDAS. No. 1, vol. 1. September 2012. 